\title{
Overexpression of Cardiac-Specific Kinase TNNI3K Promotes Mouse Embryonic Stem Cells Differentiation into Cardiomyocytes
}

\author{
Yin Wanga,b Shi-qiang Wang ${ }^{c}$ Li-peng Wang ${ }^{c}$ Yu-hong Yao ${ }^{a, b}$ Chun-yan Ma,b \\ Jin-feng Ding ${ }^{b}$ Jue $Y^{b}$ Xian-min Meng ${ }^{b}$ Jian-jun Lia,b Rui-xia Xu ${ }^{a, b}$

\begin{abstract}
aDivision of Dyslipidemia, State Key Laboratory of Cardiovascular Disease, Fu Wai Hospital, National Center for Cardiovascular Disease, Chinese Academy of Medical Sciences and Peking Union Medical College, Beijing, bState Key Laboratory of Cardiovascular Disease, Fu Wai Hospital, National Center for Cardiovascular Disease, Chinese Academy of Medical Sciences and Peking Union Medical College, Beijing, 'State Key Laboratory of Membrane Biology, College of Life Sciences, Peking University, Beijing, China
\end{abstract}

\section{Key Words}

TNNI3K • mESC • Differentiation • Cardiomyocyte

\begin{abstract}
Backgroud/Aims: The biological function of cardiac troponin I-interacting kinase (TNNI3K), a cardiac-specific functional kinase, is largely unknown. We investigated the effect of human TNNI3K (hTNNI3K) on the differentiation of mouse embryonic stem cells (mESCs) into cardiomyocytes. Methods: First, the time-space expression of endogenous Tnni3k was detected by real-time polymerase chain reaction (PCR) and western blotting at 16 different time-points over a period of 28 days. Further, action potentials and calcium current with/without $5 \mu \mathrm{M}$ nifedipine were measured by patch clamp for mESC-derived cardiomyocytes. HTNNI3K and mouse-derived siRNA were transfected into mESC using lentivirus vector to induce hTNNI3K overexpression and knock-down, respectively. Results: The number of troponin-T (cTnT) positive cells was greater in the group with TNNI3K overexpression as compared to that in control group, while less such cells were detected in the mTnni3k knock-down group as evaluated on flow cytometry (FCM) and ImageXpress Micro system. After upregulation of Connexin43, cardiac troponin-I (Ctni), Ctnt, Gata4 were detected in mESCs with TNNI3K overexpression; however, overexpression of $\alpha$-Actinin and Mlc2 $v$ was not detected. Interestingly, Ctnt, Connexin40 and Connexin45, the markers of ventricular, atrial, and pacemaker cells, respectively, were detected in by real-time PCR in TNNI3K overexpression group. Conclusion: our study indicated that TNNI3K overexpression promoted mESC differentiating into beating cardiomyocytes and induced up-regulating expression of CTnT by PKCE signal pathway, which suggested a modulation of TNNI3K activity as a potential therapeutic approach for ischemic cardiac disease.




\section{Cellular Physiology Cell Physiol Biochem 2017;41:381-398 and Biochemistry DOI: 10.1159/000456400 202017 The Author(s). Published by S. Karger AG, Basel \begin{tabular}{l|l} 
DOI: $10.1159 / 000456400$ \\
Published online: February 02, 2017 & $\begin{array}{l}\text { (c) } 2017 \text { The Author(s). Published by S. Karger AG, Base } \\
\text { www.karger.com/cpb }\end{array}$ \\
\hline
\end{tabular} \\ Wang et al.: TNNI3K and mESCs Differentiation into Cardiomyocytes}

\section{Introduction}

Cardiac troponin I-interacting kinase (TNNI3K) is a cardiac-specific kinase that belongs to the mitogen-activated protein kinase kinase kinase (MAPKKK) family [1]. TNNI3K is localized at human chromosome $1 \mathrm{p} 31.1$ within an atrioventricular septal defect critical region, as determined on bioinformatics analyses [2]. The product of this region is positioned at the sarcomere $\mathrm{Z}$ disc $[3,4]$. Tnni3k is not only transcribed in cardiomyocytes, but also finds expression in B chromosomes in roe deer fibroblasts [5]. TNNI3K is composed of three structural domains/motifs: ten copies or seven copies of an ankyrin repeat near the $\mathrm{N}$ terminal region, a Ser/Thr and Tyr kinase domain, and a C-terminal Ser-rich domain [6, 7].

Sequence comparisons of catalytic domains in combination with sequence similarities and domain structures outside the kinases indicate that this mixed-lineage kinase family belongs to the tyrosine kinase-like and the serine/threonine kinase-like groups [8]. Kinases in this family share characteristic amino acid sequences of both tyrosine and serine/threonine kinases in the catalytic domain [9]. Integrin-linked kinase (ILK), is another member of the mixed-lineage family, which, to a large extent, is similar to the TNNI3K in structure, function, and gene sequences on the chromosome [10]. Additionally, a yeast two-hybrid screen of a human bone marrow cDNA library revealed sequence homology with the designated P20, which is human immunodeficiency virus type 1 (HIV-1) gp41 core-binding molecule [6]; however, its biological properties remain poorly understood.

Different strains present different features. At present, we investigated that levels of Tnni3k mRNA and protein vary widely among inbred mouse stains. High levels of TNNI3K protein are detected in C57BL/6J and other strains, but due to a mRNA splicing mutation, little or no protein is made in DBA/2J or other strains that effectively represent naturally occurring Tnni3k-null mice [11]. The biological functions of Tnni3k exhibit a dual character. On the one hand, mice with TNNI3K overexpression exhibit only central obesity, but without in vitro evidence of myocardial necrosis or myocardial disorders [12]. Additionally, TNNI3K overexpression was shown to induce cardiomyocyte hypertrophy and accelerate hypertrophy in hypertrophic cardiomyocytes [13]. Wheeler et al. [11] found that overexpression of human TNNI3K alone exhibited no cardiac phenotype, but TNNI3K/Csq (Calsequestrin) double transgenics displayed severely impaired systolic function and reduced survival in Csq transgenic model of dilated cardiomyopathy, which suggested TNNI3K expression modified disease progression. The similar results that TNNI3K overexpression caused a dilated cardiomyopathy phenotype were detected by Tang [3]. Moreover, TNNI3K promoted ischemia/reperfusion injury, oxidative stress, and myocyte death through increased mitochondrial superoxide production and impaired mitochondrial function and is largely dependent on p38 mitogen-activated protein kinase (MAPK) activation. Last but not least, along with FPGT and H28, TNNI3K is a candidate for the viral myocarditis susceptibility 1 (Vms1) [14]. Finally, TNNI3K is closely related to acute coronary syndrome (ACS) [15], atrioventricular conduction disease [16], and obesity [17-22]. TNNI3K kinase function, would be predicted to induce cardiomyopathy or accelerate disease progression. Idiopathic cardiomyopathy patients exhibiting a precipitous decline in cardiac dysfunction might reveal such mutations. Additionally, TNNI3K activity might play different roles in other disease contexts [3,14], such as ischemic cardiac injury [23].

On the other hand, TNNI3K overexpression induced cardiac myogenesis from pluripotent P19CL6 cells by suppressing the phosphorylation of cardiac troponin I and Bax protein and reducing p38- and JNK- mediated apoptosis [23]. In a series of preliminary studies also demonstrated that TNNI3K can directly interact with cTnI through phosphorylating Ser43 and Thr143 in vitro $[9,12]$. It should be noted the implicated cTnI phosphorylation sites involve residues that have been established as protein kinase C (PKC) or protein kinase A (PKA) phosphorlation sites [24, 25]. Furthermore, multiple Ser and Thr residues in the middle and C-terminal regions of cTnT have been reported to be phosphorylated by PKC, especially PKC $\alpha$ and PKC $\varepsilon$ [26-28]. Additionally, phosphorylation of cTnT by PKC $\varepsilon$ enhanced cardiac contractility, which was reduced in heart failure due to decreased level of PKCE [26]. 


\section{Cellular Physiology Cell Physiol Biochem 2017;41:381-398

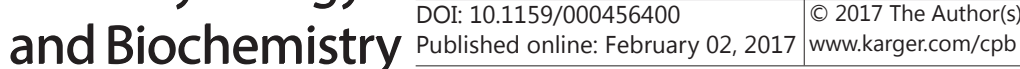

Wang et al.: TNNI3K and mESCs Differentiation into Cardiomyocytes

To better understand the effect of TNNI3K on myocyte differentiation, we induced TNNI3K overexpression and Tnni3k knockdown in mESCs and examined its effect on cardiac myogenesis in vitro. TNNI3K overexpression enhanced differentiation of mESCs into cardiomyocytes, while Tnni3k knock-down had an opposite effect.

\section{Materials and Methods}

\section{Mouse ES cell culture and differentiation}

Mouse ES cells from C57BL/6 mice were purchased from Cyagen Biosciences (Guangzhou) Inc. and cultured on irradiated ICR mouse embryonic fibroblasts (inactivated) (Stem Cell Bank/Stem Cell Core Facility, SIBCB, CAS, China) that were cultured in Dulbecco's modified Eagle's medium (DMEM; GIBCO) supplemented with $10 \%$ new born calf serum (NCS;GIBCO) for one day. Next, the mESCs were cultured in basal medium (Cyagen) supplemented with 10\% fetal bovine serum (FBS; Cyagen), $1 \mathrm{mM} \mathrm{L-glutamine(Cyagen),}$ $1 \%$ non-essential amino acids (NEAA; Cyagen), 1\% penicillin-streptomycin solution (Cyagen), $0.1 \mathrm{mM}$ 2-mercaptoethanol(Cyagen), and $1000 \mathrm{U} / \mathrm{mL}$ leukemia inhibitory factor (LIF) in a $5 \% \mathrm{CO}_{2}$ atmosphere at $37^{\circ} \mathrm{C}$. The mESC media were changed every $1-2$ days to maintain the cells in an undifferentiated state, as previously mentioned [29].

For differentiation, EBs was formed by hanging-drop method, and then, replenished the media with $10 \mu \mathrm{L}$ per EB on the 3th day during the hanging-drop phase, the EBs were transferred on to 6-well plates coated with gelatin at a concentration of approximately 20 EBs per well in the basal medium and in the mESC medium with the exception of LIF; this day was marked as day 0 of differentiation. The media were renewed every 2 days.

\section{Cell transfection}

To demonstrate the capacity of TNNI3K to accelerate cardiac myogenesis, two appropriate carriers were created, i.e., pLenti-CMV_hTNNI3K/Flag(3'flank) -IRES-EGFP and pLenti-RNAi, which are capable of carrying the hTNNI3K (NM_015978.2; http://www.ncbi.nlm.nih.gov/nuccore/NM_015978.2) or RNAi sequences (CGGTGGCAACAAGTCGCATAT) to disrupt the mESCs. Lentivirus were purchased from Cyagen Biosciences Co. and used according to the manufacturer's instructions. For lentiviral transfection, the ES cells at approximately $70 \%$ confluence were transfected with $1 \times 10^{7}$ virions each of pLenti-hTNNI3K and pLenti-Flag or pLenti-RNAi and pLenti-nonsense RNA in one well of 6-well plate. Two days after transfection, we observed green fluorescence intensity, and then isolated the target cells by flow cytometry to proceed to the next experiments.

\section{Alkaline phosphatase test}

mESCs were cultured on glass coverslips during the phase of logarithmic growth and then fixed for 10 min in cold acetone/methanol $(1: 1, \mathrm{~V} / \mathrm{V})$ on ice. The cells were lightly washed 3 times with $1 \times$ phosphatebuffered saline $(1 \times \mathrm{PBS})$ followed by the subsequent steps performed according to the recommended protocol for use of the BCIP/NBT Alkaline Phosphatase Color Development Kit (Beyotime Institute of Biotechnology, Haimen, China).

\section{Reverse transcription-polymerase chain reaction (RT-PCR) analysis}

For quantitative real-time PCR (Q-PCR) expression analysis of cardiac-associated genes, total RNA was harvested from mES cells and differentiating cells using TRIzol (Invitrogen, USA), as has been noted[30]. Contaminating DNA and protein were cleared by trichloromethane extraction and centrifuged at 15000 $\mathrm{rpm}$ at $4^{\circ} \mathrm{C}$ for $15 \mathrm{~min}$. Following isopropanol precipitation and a mild wash with $75 \%$ cool ethanol, the products were dissolved into $20 \mu \mathrm{L}$ water treated with diethyl pyrocarbonate (DEPC). First-strand cDNAs were synthesized from $0.2 \mu \mathrm{g}$ of total RNA using the SuperScript III First-Stand Synthesis SuperMix for qPCR (Invitrogen, Carlsbad, CA, USA). Using CDNA as the template, real-time PCR assays supplemented with SYBR Green (Applied Biosystms) were performed in triplicate using the ABI Prism 7500 HT sequence detection system (Applied Biosystems), according to the manufacturer's instructions. The data were normalized to glyceraldehydes-3-phosphate dehydrogenase (Gapdh), and the gene expression levels normalized to that of day- 6 cells. The primers utilized are listed in Table 1. 


\section{Cellular Physiology Cell Physiol Biochem 2017;41:381-398

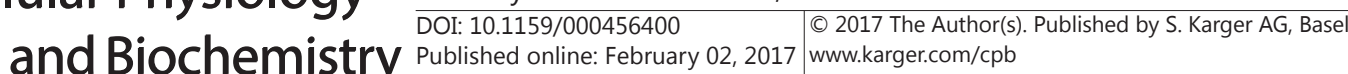

Wang et al.: TNNI3K and mESCs Differentiation into Cardiomyocytes

Western blotting for relative proteins

The cells or EBs were harvested as mentioned above, while harvested on the 22th day of EBs differentiation to detect the relative proteins of the signaling pathway; washed twice with PBS, and lysed with cool radioimmunoprecipitation assay buffer (RIPA, Applygen Technologies Inc., Beijing, China) containing protease inhibitors, phosphatase inhibitors and phenylmethyl sulfonyl fluoride (PMSF) for $30 \mathrm{~min}$ on ice. The lysates were centrifuged at 13,000 rpm for $15 \mathrm{~min}$ at $4^{\circ} \mathrm{C}$; the cell homogenates (50 $\mu$ g protein) were separated by $10 \%$ SDS-polyacrylamide gel electrophoresis and transferred on to a nitrocellulose membrane (Millipore, Germany). The membranes were blocked by TBS-T $(137$ $\mathrm{mM} \mathrm{NaCl}, 20 \mathrm{mM}$ Tris (pH 7.6), and $0.1 \%$ (v/v) Tween 20) supplemented with 5\% $(\mathrm{w} / \mathrm{v})$ nonfat dry milk at room temperature (RT) for 2 hours. The membranes were then incubated overnight at $4^{\circ} \mathrm{C}$ with cardiac antibodies; incubated with secondary HRPIgG antibodies (ZSGB-BIO; diluted 1:5000 in TBS-T) for 1 hour at RT. The volumes of the protein bands were quantified with a Bio-Rad Chemi DocTM EQ densitometer and Bio-Rad Quantity One Software (BioRad laboratories, Hercules, USA). GAPDH was used as an internal control. The cardiac-specific protein antibodies used for
Table 1. Primers used for real-time PCR. Tm, annealing temperature

\begin{tabular}{|c|c|c|c|}
\hline Gene name & Size (bp) & primers & $\operatorname{Tm}\left({ }^{\circ} \mathrm{C}\right)$ \\
\hline \multirow[t]{2}{*}{$\overline{I s l-1}$} & 101 & 5'-CACACCTTGCGGACCTGCTAT-3' & 58 \\
\hline & & 5'-ACTCGGATGACTCTGGGACTGA-3' & \\
\hline \multirow[t]{2}{*}{ flk-1 } & 180 & 5'-CATTATCCTCGTCGGCACTG-3' & 56 \\
\hline & & 5'-CTGGCATCATAAGGCAAGCG-3' & \\
\hline \multirow[t]{2}{*}{ cTnT } & 186 & 5'-AGACTGGAGTGAAGAAGAGGAGGAC-3' & 58 \\
\hline & & 5'-CTGGGCTTGGGTTTGGTGT-3' & \\
\hline \multirow[t]{2}{*}{ cTnI } & 127 & 5'-CCATAGGCATTGAGACCCAC-3' & 56 \\
\hline & & 5'-CGTTCCATCTCCTGCTTCG-3' & \\
\hline \multirow[t]{2}{*}{ MLC-2 } & 199 & 5'-GACCATTCTCAACGCATTCA-3' & 56 \\
\hline & & 5'-TTCTCCGTGGGTAATGATGT-3' & \\
\hline \multirow[t]{2}{*}{ hTNNI3K } & 141 & 5'-TGAAGTTGGAGATAGACCCC-3' & 55 \\
\hline & & 5'-CGAGAACAGAAATGGAGTGG-3' & \\
\hline \multirow[t]{2}{*}{ MHC6 } & 154 & 5'-GCAGCAGAACCCACCCAAGT-3' & 58 \\
\hline & & 5'-ATAGGGGTTGACGGTGACGC-3' & \\
\hline \multirow[t]{2}{*}{ mTNNI3K } & 156 & 5'-GGCACACAGGATTACACTCT-3' & 55 \\
\hline & & 5'-TCTCATAAGCCCACATCAAA-3' & \\
\hline \multirow[t]{2}{*}{ connexin 43} & 135 & 5'-CCTTTCGCTGTAACACTCAA-3' & 55 \\
\hline & & 5'-CGTGAGCCAAGTACAGGAGT-3' & \\
\hline \multirow[t]{2}{*}{ Gata4 } & 183 & 5'-AATCTAAGACGCCAGCAGGT-3' & 56 \\
\hline & & 5'-CTGCTGTGCCCATAGTGAGA-3' & \\
\hline \multirow[t]{2}{*}{ a-actinin } & 197 & 5'-CTATACAACCATCACGCCTCAG-3' & 56 \\
\hline & & 5'-AAATCCTCССАAТCTCCTCC-3'-3' & \\
\hline \multirow[t]{2}{*}{ gapdh } & 213 & 5'-AATGGATTTGGACGCATTGGT-3' & 60 \\
\hline & & 5'-TTTGCACTGGTACGTGTTGAT-3' & \\
\hline \multirow[t]{2}{*}{ connexin 40} & 217 & CCACAGTCATCGGCAAGGTC & 58 \\
\hline & & CTGAATGGTATCGCACCGGAA & \\
\hline \multirow[t]{2}{*}{ connexin 45} & 198 & AGATCCACAACCATTCGACATTT & 58 \\
\hline & & TCCCAGGTACATCACAGAGGG & \\
\hline
\end{tabular}

Western blotting were as follows: monoclonal anti-cardiac troponin T antibody (1:1000; Abcam); polyclonal anti-troponin I (1:500; Santa Cruz); myosin light chain 2 polyclonal antibody (1:500; Proteintech Group, Inc., USA); MYH6 polyclonal antibody (1:500; Proteintech) and anti-actinin á N-terminal, antibody (1:500; SigmaAldrich); monoclonal anti-GATA4 antibody (1:500; Abcam); monoclonal anti-connexin43 antibody (1:500; Santa Cruz); monoclonal anti-Nkx2.5 antibody (1:500; Santa Cruz); p-PKCe(Ser729) (1:200; Santa Cruz); PKC $(22 B 10)$ Rabbit mAb(1:1000, CST); $\varepsilon V 1-2$ (PKC $\varepsilon$ inhibitor peptide) (1 $\mu$ M, Santa Cruz); Phospho-p38 MAPK (Thr180/Tyr182) Rabbit mAb (1:1000, CST); Phospho-p44/42 MAPK (Erk1/2) (Thr202/Tyr204) Rabbit mAb (1:1000, CST); Phospho-MAPK/JNK (Thr183/Tyr185) Rabbit mAb (1:1000, CST); monoclonal anti-GAPDH antibody (1:1000; Abcam); and polyclonal anti-TNNI3K antibody (1:1000; Abcam). The secondary antibodies used were: HRP-conjugated goat anti-rabbit IgG $(\mathrm{H}+\mathrm{L})$, and HRP-conjugated goat antimouse IgG (H+L) (1:5000; Immunology Consultants Laboratory, Inc.).

\section{Immunofluorescence}

Cells or EBs were grown on glass coverslips in the absence of gelatin; fixed for 5 min in cold acetone/ methanol $(1: 1, \mathrm{v} / \mathrm{v})$, and allowed to air-dry for $30 \mathrm{~s}$. The cells or EBs were incubated with $5 \%$ normal goat serum (NGS; ZSGB-BIO, Beijing, China) in PBS for one hour at RT and incubated with the primary antibody overnight at $4^{\circ} \mathrm{C}$. After incubated at $37^{\circ} \mathrm{C}$ for $45 \mathrm{~min}$, these EBs were incubated with the secondary antibody conjugated with FITC488 in the absence of bright light and mounted with fluorescent mounting medium, and then observed with a confocal scanning laser microscope (Sp8; Leica, Germany).

Immunostaining with anti-SSEA-1 (1:100; EMD Millipore Co., Massachusetts, USA) and anti-Oct-4 (1:100; EMD Millipore Co., Massachusetts, USA) was used to verify the undifferentiated mESCs. To verify cardiac differentiation, the following antibodies were used: monoclonal anti-cardiac troponin $\mathrm{T}$ antibody 


\section{Cellular Physiology Cell Physiol Biochem 2017;41:381-398 and Biochemistry Published online: February 02, 2017 www.karger.com/cpb}

Wang et al.: TNNI3K and mESCs Differentiation into Cardiomyocytes

(1:100; Abcam); anti-cardiac troponin I antibody (1:100; Abcam); myosin light chain 2 polyclonal antibody (1:100; Proteintech Group, Inc., USA); MYH6 polyclonal antibody (1:100; Proteintech); and anti-actinin á $\mathrm{N}$-terminal antibody (1:50; Sigma-Aldrich).

The secondary antibody used in this study was fluorescein (FITC)-conjugated AffiniPure goat antirabbit IgG $(\mathrm{H}+\mathrm{L})$ (1:300; Proteintech). The cell nuclei were counterstained with $0.1 \%$ 4', 6-diamidino-2phenylindole (DAPI; ZSGB-BIO).

\section{Transmission electron microscopy (TEM)}

The EBs were fixed in cold 2.5\% glutaraldehyde with $4 \%$ paraformaldehyde in $0.1 \mathrm{~mol} / \mathrm{L}$ cacodylate buffer (pH 7.4) followed by post-fixed in 1\% osmium tetroxide, dehydrated and embedded in Epon resin. Ultrathin sections were mounted on copper grids, stained with uranyl acetate and lead citrate, and examined by TEM (Philips).

\section{Electrophysiology}

EBs cultured on the $22^{\text {nd }}$ day (dispersed condition) were dispersed by $0.1 \%$ collagenase type I and $0.1 \%$ collagenase type II (Roche) in ADS buffer (116 mM NaCl, 20 mM HEPES, 12.5 mM NaH2PO4, 5.6 $\mathrm{mM}$ glucose, $5.4 \mathrm{mM} \mathrm{KCl}$, and $0.8 \mathrm{mM} \mathrm{MgSO} 4$, pH 7.35) by stirring. The dispersed EBs were cultured for 2 days in DMEM a glass dish at $37^{\circ} \mathrm{C}$ supplemented with $10 \%$ FBS. The microscope was equipped with a recording chamber and a noise-free heating plate (Microwarm Plate; Kitazato Supply). A $10 \mathrm{mmol} / \mathrm{L}$ volume of HEPES was added to the culture medium to maintain the $\mathrm{pH}$ of the perfusate at 7.5-7.6. Standard glass microelectrodes that had a DC resistance of 25-35 $\mathrm{M} \Omega$ when filled with pipette solution (2mol/L KCl) were used. The electrodes were positioned using a motor-driven micromanipulator (EMM-3SV; Narishige) under optical control.

Spontaneously beating cells were selected as targets, and the action potentials and calcium current of the targeted cells recorded. Axon patch 200B (Axon Instruments, Sunnyvale, USA) was used for whole cell patch clamp recordings; data acquisition was controlled by Axon Instruments pClamp10 software via a Digidata 1440 acquisition system. Under current-clamp mode, action potentials (APs) of mESC-derived cardiomyocytes were recorded with whole cell patch-clamp configuration in Tyrode's solution (in mM): 137 $\mathrm{NaCl}, 5.4 \mathrm{KCl}, 1.8 \mathrm{CaCl}_{2}, 1 \mathrm{MgCl}_{2}, 10$ Hepes, 10 Glucose, adjusted to $\mathrm{pH}=7.4$ with $\mathrm{NaOH}$. The glass pipette was filled with the pipette solution (in mM): $120 \mathrm{KCl}, 5$ EGTA, $1 \mathrm{MgCl}_{2}, 5 \mathrm{Na}$ ATP, 10 HEPES, adjusted to $\mathrm{pH}=7.4$ with $\mathrm{KOH}$. Experiments were performed at RT, as has been noted [31-33].

$\mathrm{Ca} 2+$ currents were measured in voltage-clamp mode at RT. Both cells were recorded with the external solution (in mM): $135 \mathrm{NaCl}, 5 \mathrm{CsCl}, 1 \mathrm{CaCl}_{2}, 1 \mathrm{MgCl}_{2}, 1.2 \mathrm{NaH}_{2} \mathrm{PO}_{4} 10$ Hepes, 10 Glucose, $20 \mu \mathrm{M}$ TTX, adjusted to $\mathrm{pH}=7.4$ with $\mathrm{NaOH}$. The patch pipettes had resistances of 2-4 $\mathrm{M} \Omega$ when filled with a solution containing (in mM), $120 \mathrm{CsCl}, 1 \mathrm{MgCl}_{2}, 5 \mathrm{MgATP}, 20 \mathrm{TEACl}, 5$ EGTA and $10 \mathrm{HEPES}$, adjusted to $\mathrm{pH}=7.2$ with CsOH. The external solution with $5 \mu \mathrm{M}$ nifedipine was used to block the L-type Ca2+ currents. For $\mathrm{Ca}^{2+}$ current density $(\mathrm{pA} / \mathrm{pF})$, currents were normalized to the cell capacitance and expressed in $\mathrm{pA} / \mathrm{pF}$.

\section{Statistical analysis}

Data are presented as mean \pm Standard Deviation; between-group differences were compared using one-way Analysis of Variance (ANOVA) followed by Student $t$ test. $P$-values $<0.05$ were considered indicative of a statistically significant difference. A minimum of three independent experiments were performed for each analysis. All calculations were analyzed with SPSS Statistics 20 software.

\section{Results}

Morphological characteristics of undifferentiated and differentiated mESCs

Mouse ES cells formed nodule-shaped or oval colonies with distinct boundaries on the MEFs on the $2^{\text {nd }}$ day (Fig. 1 (1) b) and then appeared like nested colonies (Fig. 1 (1) c). The proliferative mESCs were digested into single cells and hung on inside cover of $150 \mathrm{~mm}$ Petri dish in 10\% FBS containing differentiation media. These cells continued to proliferate and to gradually thicken and form EBs with globular-shaped structures (Fig. 1 (1) d-e). 


\section{Cellular Physiology Cell Physiol Biochem 2017;41:381-398 \begin{tabular}{ll|l} 
DOI: 10.1159/000456400 & & 2017 The Author(s). Published by S. Karger AG, Basel \\
\hline
\end{tabular}

Fig. 1. Morphological changes in mouse e mbryonic fibroblasts (MEFs) and phenotypic characteristics of mESCs. (1) Undifferentiated and differentiated $\mathrm{mE}$ SCs. (a): The morphology of the MEFs cultured for $24 \mathrm{~h}$. (b-c): Colonies of mESCs cultured on MEFs for 2 days and 4 days. (de): Embryoid bodies (EBs) from the hanging drop culture method at 2 days and 4 days. (f-h): Representative EB from the adherent method cultured for 2 days, 4 days and 10 days. (i): Spontaneously beating cell clusters were found in the cultured cells (the red arrow indicates bea-
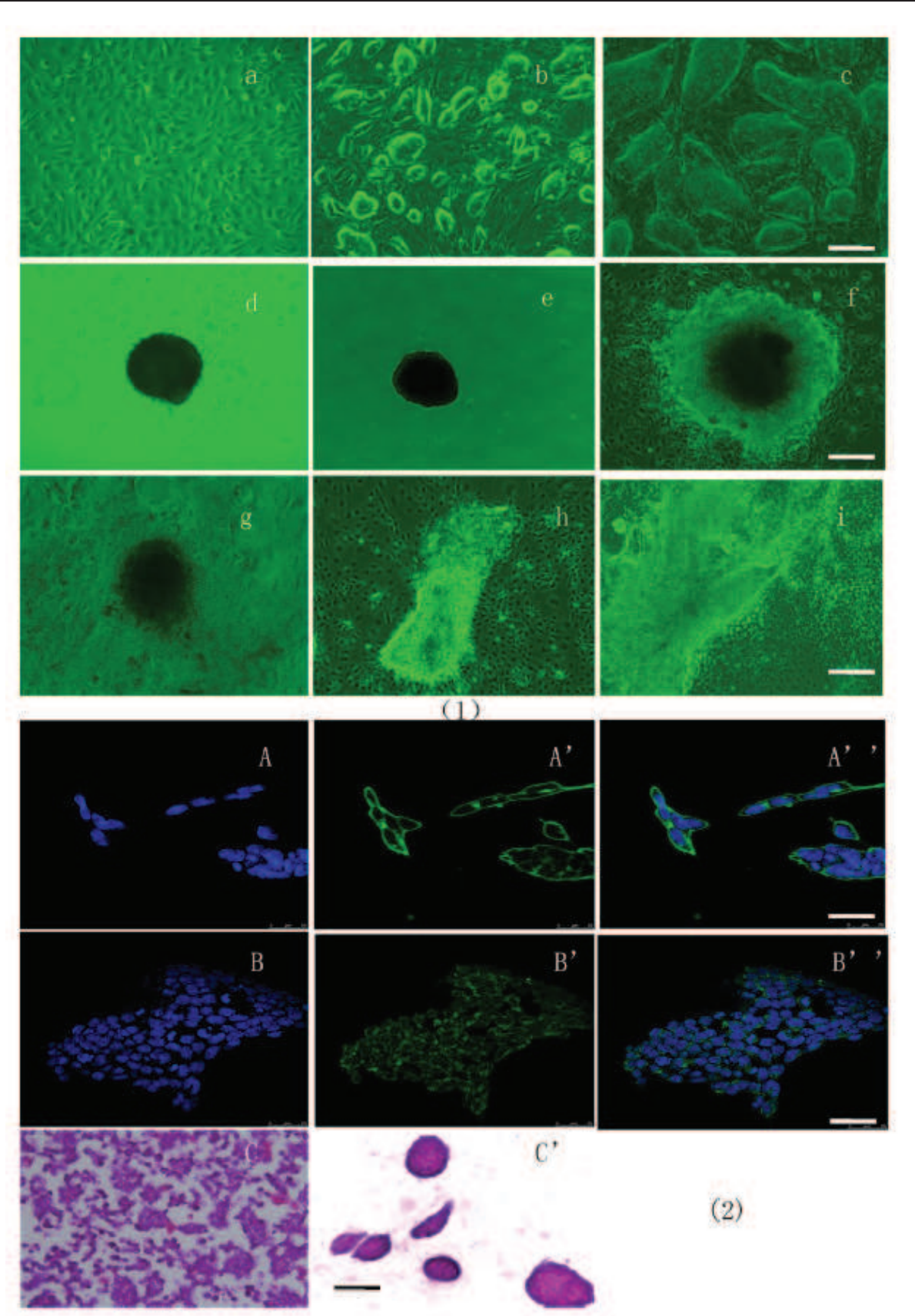

ting cell clusters). Scale bars=100 ìm. (2) Biochemical characterization of the mESCs. (A-B"): Pluripotency marker expression in the undifferentiated mESCs. (A): Nuclear counterstaining with DAPI (blue). (A'): SSEA1. (A"): Merged image. (B): Nuclear counterstaining with DAPI (blue). (B'): Oct-4. (B"): Merged image. (C): Hematoxylin-eosin staining (H.E). (C'): Alkaline phosphatase staining (ALP). Scale bars: A and B=25 $\mu \mathrm{m}, \mathrm{C}$ $=100 \mu \mathrm{m}, \mathrm{C}^{\prime}=25 \mu \mathrm{m}$.

We found that the cells gradually grew from the edges of the EBs after $24 \mathrm{~h}$ of adherent culture to form growth halos which gradually increased in size (Fig. 1 (1) f-h). Furthermore, the cell clusters in the central part of the EBs began to spontaneously beat 30 - 50 times / min after the $16^{\text {th }}$ day of adherent culture (Fig. 1 (1)). These findings suggest successful differentiation of mESCs into cardiomyocytes. 

Cellular Physiology Cell Physiol Biochem 2017;41:381-398 and Biochemistry DOI: 10.1159/000456400 2017 The Author(s). Published by S. Karger AG, Basel and Biochemistry Publisned on

Fig. 2. The expression of gene and protein expression during the course of mESCs differentiating into cardiomyocytes. (1) Temporal gene expression analyses were performed over 28 days (16 time points) on the cultures of the mESCs differentiating into cardiomyocytes: Flk-1 (undifferentiated mESCs), Isl-1 (cardiac progenitor cell marker), Gata4 (early cardiac transcription factors), Mlc2, Mhc6, Connexin43, $\alpha$-actinin, Ctni, Ctnt (mature cardiomyocytes markers) and Tnni3k. Total mRNA detected at each time point was subjected to reverse-transcription PCR (RT-PCR) followed by real-time PCR analysis of gene expression. All gene expression levels were normalized to those of the undifferentiated stem cells using the 2- $\Delta \Delta \mathrm{Ct}$ method and normalized to Gap$d h$. The day of the first adherent culture was marked as day 0 . The samples of undifferentiated and differentiated mESCs were collected synchronously with the samples collected for mRNA. The space-time patterns of expression of the cardiac-specific markers are presented in (2) and (3). (4) The quantitative western blotting data were obtained with Quantity One Software and are summarized as the means \pm the SDs after normalization to GAPDH.
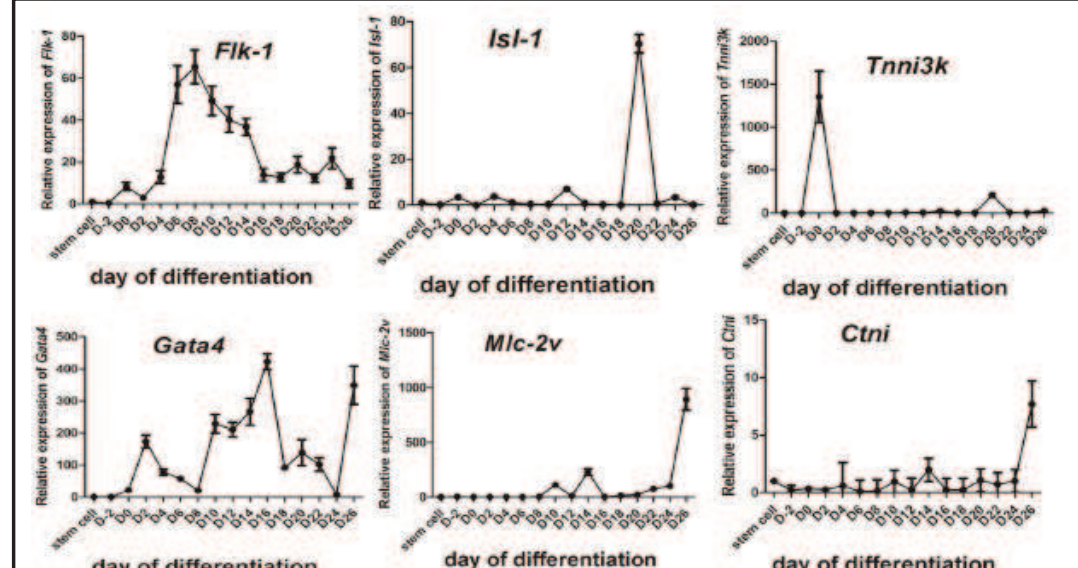

day of differentiation

day of differentiation

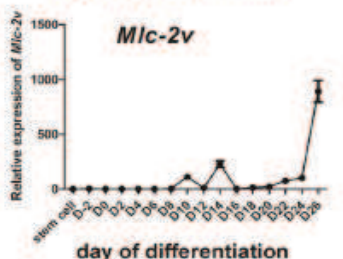

Ctni
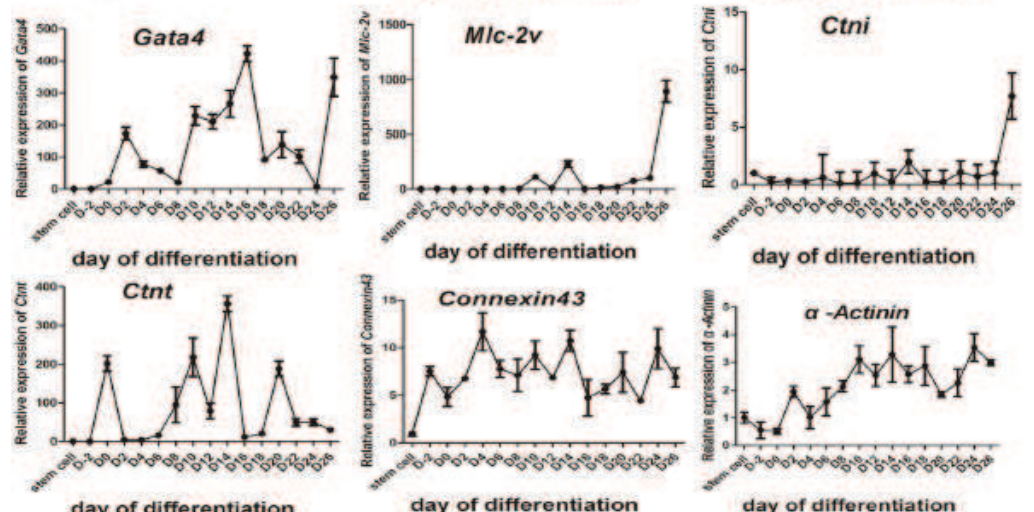

(1)

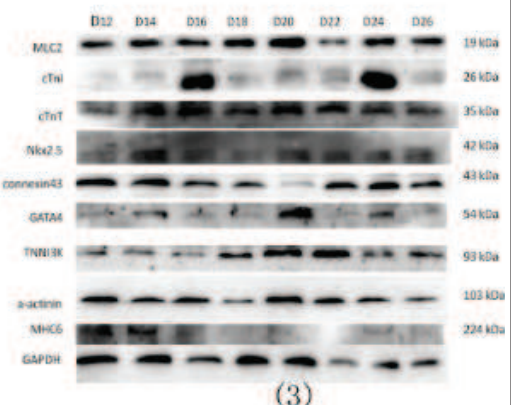

(2)

(3)
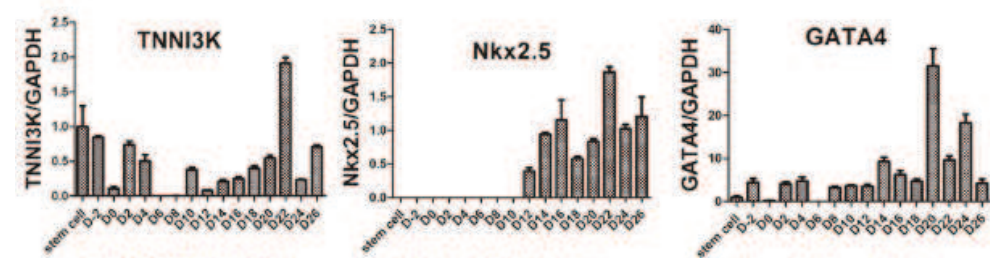

day of differentiation

day of differentiation
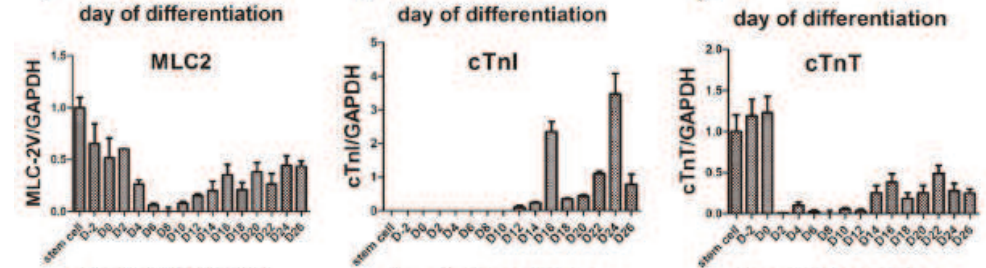

day of differentiation

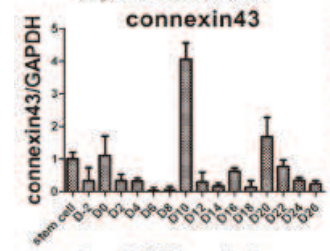

day of differentiation
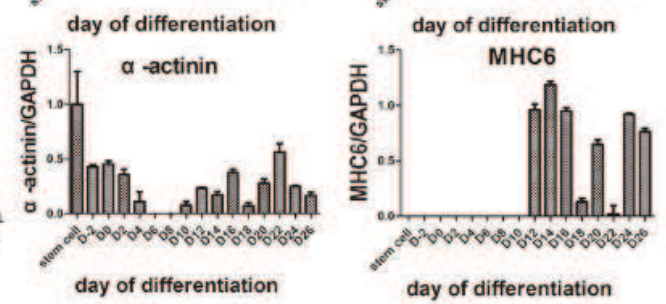

(4) 


\section{Cellular Physiology Cell Physiol Biochem 2017;41:381-398 \begin{tabular}{l|l|l}
\hline and & DOI: 10.1159/000456400 & $\begin{array}{l}\text { C } 2017 \text { The Author(s). Published by S. Karger AG, Basel } \\
\text { www.karger.com/cpb }\end{array}$ \\
\hline
\end{tabular}}

Wang et al.: TNNI3K and mESCs Differentiation into Cardiomyocytes

Fig. 3. In situ detection of cardiac-specific proteins in differentiated mES cells by immunofluorescence, after 22 days of spontaneous differentiation. (A-A"): Differentiated mESC-derived cardiomyocytes expressing MLC2. (A): Nuclear counterstaining with DAPI (blue). (A'): MLC2. $\left(A^{\prime \prime}\right)$ : Merged image. (B): Nuclear counterstaining with DAPI (blue). (B'): Cardiac troponin-I. (B"): Merged image. (C): Nuclear counterstaining with DAPI (blue). (C'): Cardiac troponin-T. (C'): Merged image. (D): Nuclear counterstaining with DAPI (blue). (D'): $\alpha$-actinin. (D"): Merged image. Scale bars $=25 \mu \mathrm{m}$.
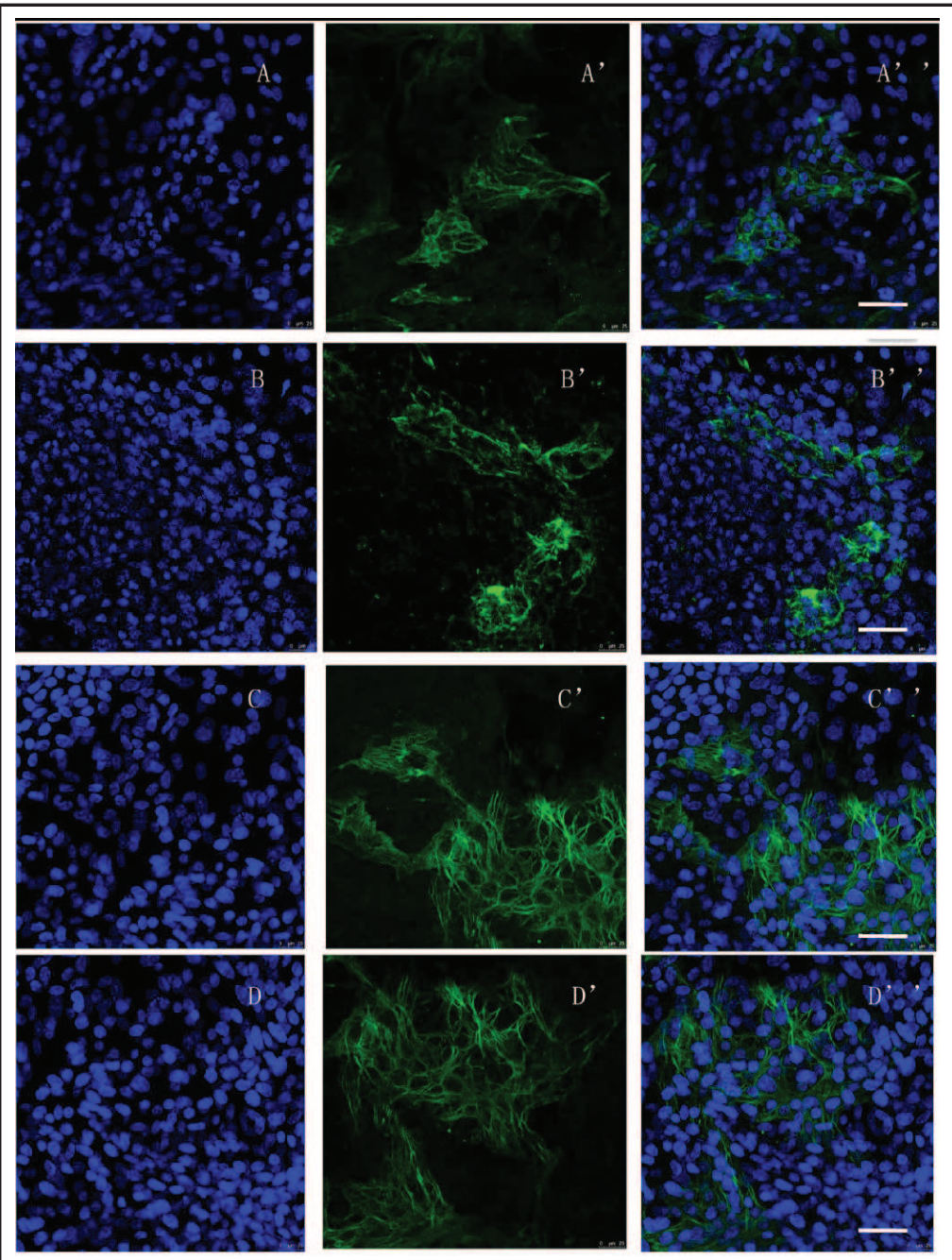

Expression of embryonic-specific proteins in mESCs

To further confirm that the mESCs had not differentiated into other types of cells, the expression of two specific proteins, i.e., SSEA-1 and Oct-4, was examined by immunofluorescence (Fig. 1 (2) A-B"). A vast majority of mESCs were blue colored, and red HE-stained cells were rarely observed (Fig. 1 (2) C); these findings implied a nucleocytoplasmic ratio $>1$ in the undifferentiated mESCs. Further, the pluripotent mESCs were rich in ALP and stained bluish violet (Fig. 1 (2) C). This suggested that the cells had maintained their status as undifferentiated stem cells.

Expression levels of cardiac-specific genes and the corresponding proteins in the mESCS following differentiation into cardiomyocytes

To thoroughly verify the successful differentiation of mESCs into cardiomyocytes, the space-time expression patterns of mouse cardiac-specific genes and proteins, i.e., Isl-1, Flk1, MLC2, $\alpha$-actinin, MHC6, connnexin43, cTnT, cTnI, GATA4, and TNNI3K, were examined. These genes were examined with real-time PCR based on cDNA by the primers shown in Table 1, and the proteins were examined by western blotting and immunofluorescence.

To confirm that the EBs continued to be comprised of undifferentiated mESCs, the space-time expression pattern of Flk-1, a marker of multipotent ESCs, and found a bellshaped gene expression pattern of Flk-1; a gradual increase was first observed, followed by a peak on day 8, and a subsequent gradual reduction. The cardiac progenitor marker Isl-1 was expressed at a low level that only increased briefly between day 18 and 22 . These findings

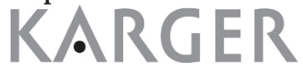




\section{Cellular Physiology \\ Cell Physiol Biochem 2017;41:381-398 and Biochemistry

Fig. 4. Ultramicrostructure of the mES cells following differentiation into cardiomyocytes. The ultramicrostructures of the mature cardiomyocytes possessed a specific biological marker, i.e., sheath -like myofibers. Scale bar $=0.5 \mu \mathrm{m}$.

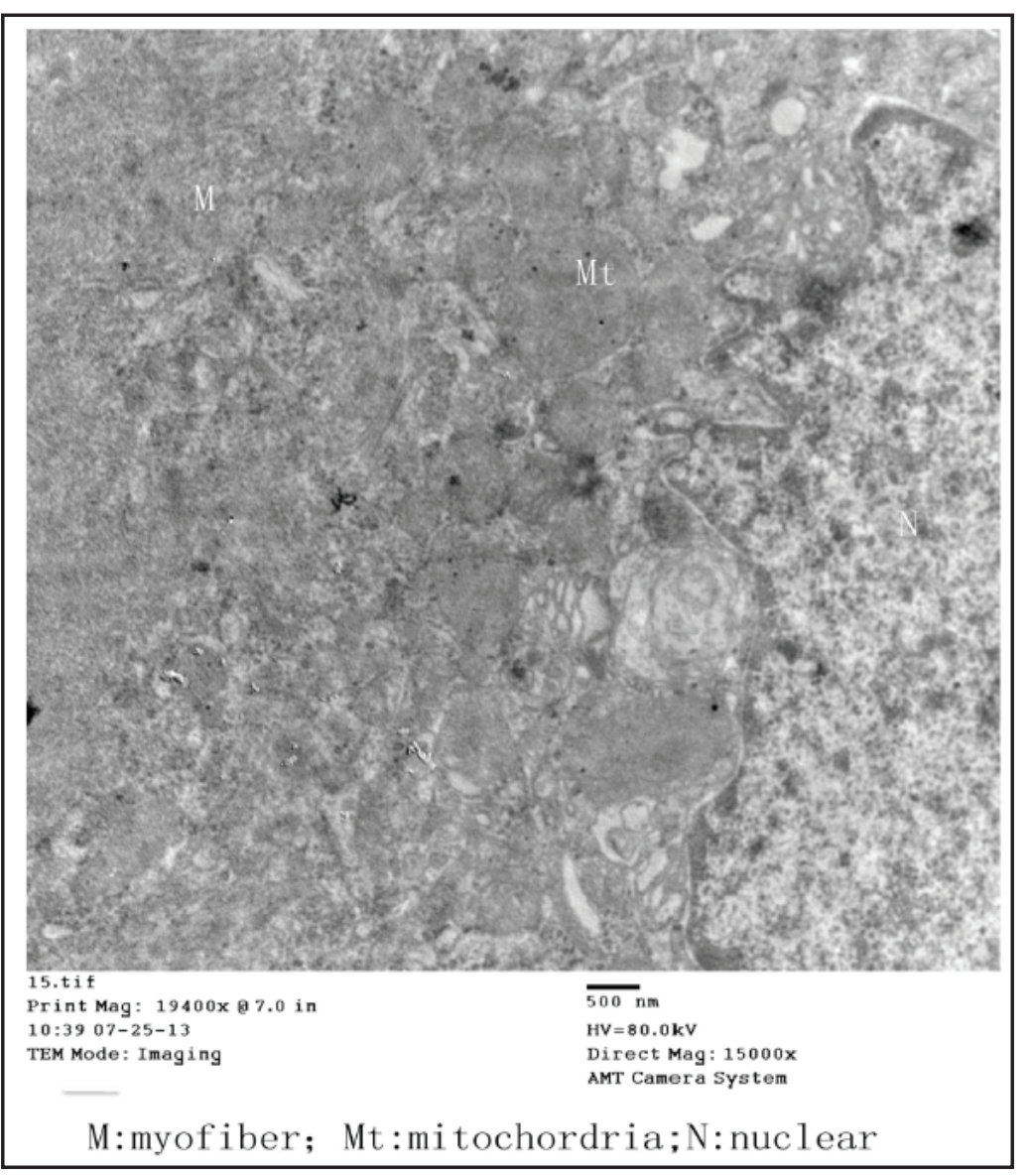

indicated that the numbers of new cardiomyocytes remained low. We speculated that none of these genes were highly expressed in the absence of an inducer at any time during the spontaneous differentiation of mESCs into cardiac myocytes. The initial expression of the cardiac transcription factor Gata4 was detected on differentiation day-1, which abruptly disappeared on day 24. The expression of the cardiac-specific genes Mlc2, Mhc6, $\alpha$-Actinin, Ctni, Ctnt, and Connexin 43 were detected initiated between day-0 and day-2; their expression levels were subsequently strongly upregulated to varying degrees. Interestingly, the expression of Tnni3k peaked at day-2 and decreased thereafter (Fig. 2 (1)).

To further characterize the space-time expression patterns of the cardiac-specific markers, we examined the expression characteristics of GATA4, Nkx2.5, MLC2, myosin heavy chain-6 (MHC6), cTnI, cTnT, connexin43, and $\alpha$-actinin proteins. The expression of cTnT, MLC2, $\alpha$-actinin, and TNNI3K proteins was detected in the early stage followed by a sharp decrease and a gradually increase, thereafter. Interestingly, proteins, such as cTnI, MHC6, and Nkx2.5, were rarely observed before day 12 (Fig. $4 \mathrm{a}, \mathrm{g}$, j). The remaining proteins were expressed at low levels in the early stage, suddenly increased and then decreased (Fig. 2 (2$4)$ ). When the mESCs-derived cardiomyocytes exhibited robust beating and contraction on the $22^{\text {th }}$ day of differentiation, we detected the expression and location of the markers for cardiomyocytes including MLC2, cTnI, cTnT, and $\alpha$-actinin (Fig. 3).

\section{Ultramicrostructure of mESC-derived cardiomyocytes on TEM}

To detect the inner structures of the mESC-derived cardiomyocytes, we collected beating EBs on day 22 and observed numerous myofibers and mitochondria (Fig. 4). These findings further demonstrated that our method of differentiating mESCs into cardiomyocytes was successful. 


\section{Cellular Physiology Cell Physiol Biochem 2017;41:381-398

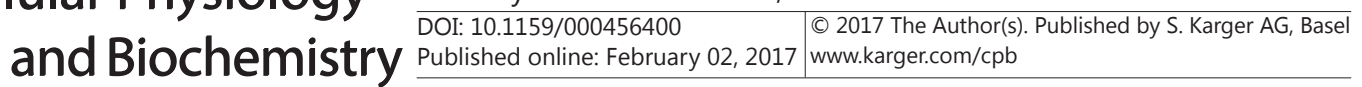 \\ Wang et al.: TNNI3K and mESCs Differentiation into Cardiomyocytes}

Fig. 5. Action potential and calcium current properties of mESC-derived cardiomyocytes by patch clamp. A-F: Traces of spontaneous action potentials measured in V-like $(\mathrm{n}=12), \mathrm{N}$-like $(n=2)$, and A-like $(n=5)$ from cardiomyocytes derived from mESC. G: Traces of calcium current with/ without $5 \mu \mathrm{M}$ nifidepine in cardiomyocytes derived from mESC. H: Bar graph shows the averaged maximum peak calcium current density $(\mathrm{pA} / \mathrm{pF})$. Values given are mean $\pm \operatorname{SEM}(n=5)$.

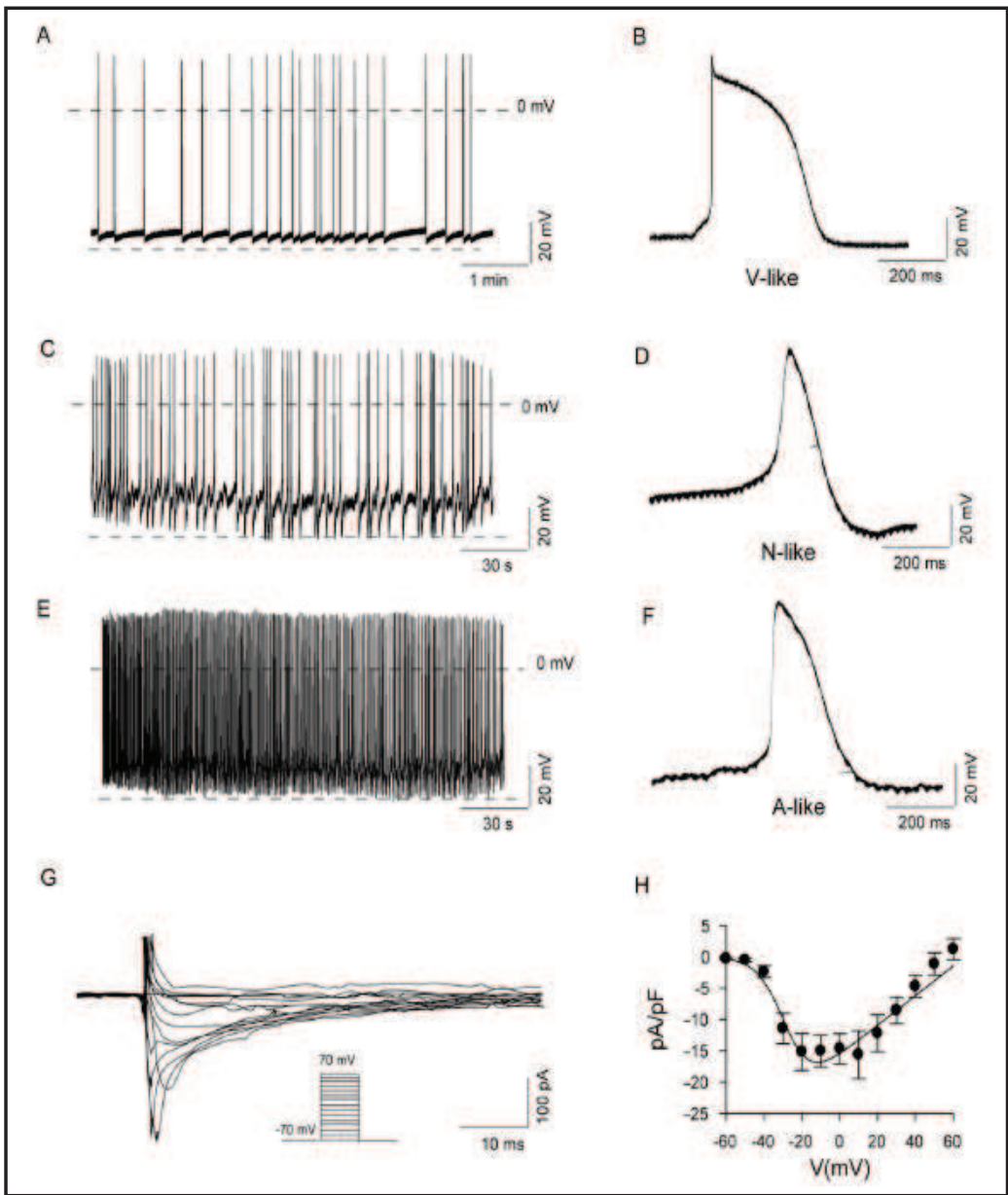

Action potential and calcium current recordings of mESC-derived cardiomyocytes

We recorded the action potentials of mESC-derived cardiomyocytes using glass microelectrodes. 22-day-old beating EBs were selected manually and dispersed into small clumps and single cells. The dispersed EBs were cultured for two days before analysis. The microelectrode was advanced to the intracellular cytoplasm and the voltage of the bulk solution and cytoplasm were measured. Rhythmic beating could be detected in the mESCderived cardiomyocytes. We measured fewer spontaneously beating ventricular-like $(\mathrm{n}=$ $12)$, atrial-like $(n=5)$ and nodal-like $(n=2)$ cells due to their relatively lower proportions in mESC-derived cardiomyocytes and because of the difficulty in finding single cells for pacing. (Fig. 5 A-F). Calcium current was recorded as above with or without $5 \mu \mathrm{M}$ nifedipine. (Fig. 5 G-H).

TNNI3K overexpression promoted cardiomyogenesis, and strengthened the expression of cardiac-specific markers

We calculated the numbers of beating EBs at five time-points and counted the cTnT-positive cells with FCM following TNNI3K-overexpression and Tnni3k-knockdown lentivirus treatment (Fig. 6). We observed increased numbers of beating ESs in the TNNI3Koverexpression groups and reduced numbers in the Tnni3k-knockdown groups. Similar results were observed for the numbers of cTnT-positive cells. Additionally, we found that the expression of the cardiac-specific genes was markedly increased in the TNNI3K overexpression group and significantly decreased in the Tnni3k knockdown group (Fig. 7). Furthermore, cTnT and MHC6 co-staining was observed in the TNNI3K-overexpression 


\section{Cellular Physiology Cell Physiol Biochem 2017;41:381-398

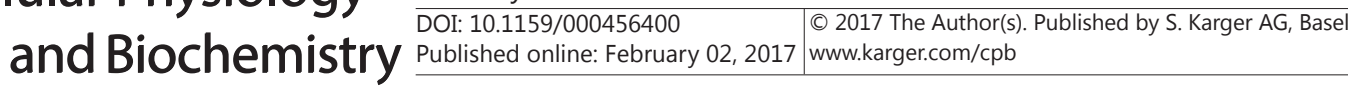 \\ Wang et al.: TNNI3K and mESCs Differentiation into Cardiomyocytes}

Fig. 6. Flow cytometry and ImageXpress Micro detection for cTnT+ cells. (a-b): TNNI3K overexpression (hTNNI3K) increased the number of beating EBs, and Tnni3k knockdown (siRNA) produced the opposite effect. TNNI3K overexpression strengthened the expression of cardiac troponin $\mathrm{T}$, and Tnni3k knockdown elicited the opposite effect. Normal: spontaneously differentiated cardiomyocytes. hTNNISK: TNNI3K overexpression, Flag-only: the control of TNNI3K overexpression, siRNA: Tnni3k knockdown, control: non-sense RNA.

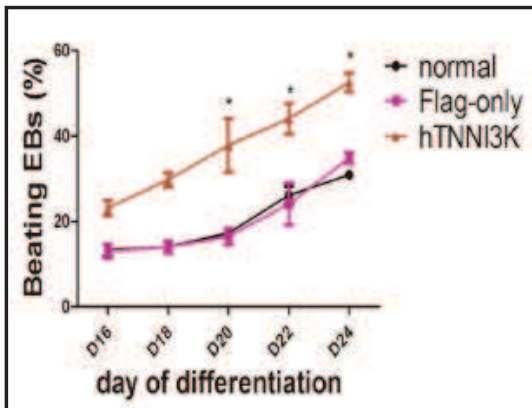

a

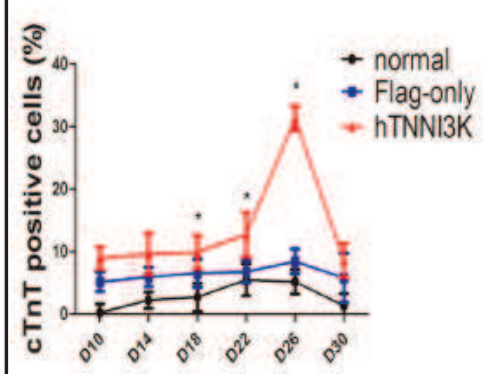

day of differentiation

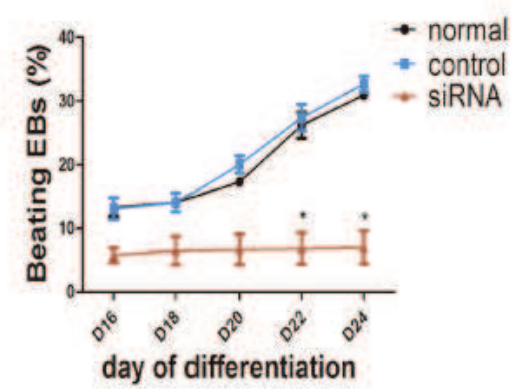

b

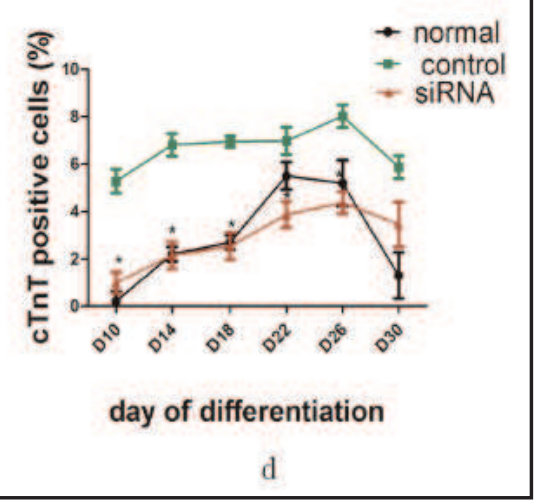

group but not in the Tnni3k-knockdown or normal control groups. Interestingly, TNNI3K overexpression induced subcellular myogenesis, including that of ventricular and atrial pacemaker cells as assessed by real-time PCR for cTnT, connexin 40 and connexin45, respectively. In addition, TNNI3K suppressed phosphorylation of p38, Erk1/2 and JNK (Fig. 8).

TNNI3K overexpression up-regulates the expression of cTnT by PKCE

To define the relationship of TNNI3K, PKC $\varepsilon$ and cTnT, these EBs were divided into 4 groups, namely, hTNNI3K group, h-cntl group, siRNA group and si-cntl group. Furthermore, each group was divided into two sub-group, which were administrated by $\varepsilon$ V1-2 $(1 \mu \mathrm{M})$, an inhibitor peptide of $\mathrm{PKC} \varepsilon$, and $0.09 \% \mathrm{NaCl}$ for $20 \mathrm{~min}$, respectively. In hTNNI3K group, the expression of cTnT was downregulated by $\varepsilon$ V1-2, as well as the expressions of PKC $\varepsilon / p-P K C \varepsilon$, while the expression of TNNI3K was not changed by $\varepsilon$ V1-2. In siRNA group, the expression of PKC $\varepsilon$ was downregulated by siRNA of TNNI3K (Fig. 9).

\section{Discussion}

The role of TNNI3K in differentiation of mESC into cardiomyocytes and the underlying mechanisms are not well characterized. TNNI3K overexpression effectively increased the number of mESC derived-cardiomyocytes, while down-regulation of Tnni3k had an opposite effect. Our findings underline the role of TNNI3K in inducing mESC differentiation into cardiomyocytes.

TNNI3K is a cardiac-specific kinase that interacts specifically with cardiac troponin I and belongs to the MAPKKK family according to Ding [1]. After investigating the biological function of TNNI3K, we found that its $\mathrm{C}$-terminal region inhibits kinase activity, while the $\mathrm{N}$-terminal seven or ten ANK domain is involved in autophosphorylation. TNNI3K, located in the nucleus, may be a genetic marker of accelerated disease progression, which contrasts with the wellknown marker pro-atrial natriuretic peptide (proANP) that present in the cytosol of myocar- 


\section{Cellular Physiology Cell Physiol Biochem 2017;41:381-398 and Biochemistry DOI: 10.1159/000456400 202,2017 2017 The Author(s). Published by S. Karger AG, Basel \\ Wang et al.: TNNI3K and mESCs Differentiation into Cardiomyocytes}

Fig. 7. TNNIBK overexpression induced and Tnni3k knockdown inhibited cardiomyogenesis in mESCs. (A): Real-time PCR detection of the effects of TNNI3K overexpression (hTN$N I 3 K)$ on cardiac-specific genes. (B-C): Western blot detection of the effects of TNNI3K overexpression on cardiac-specific genes. (D): Real-time PCR detection of the effects of Tnni3k knockdown (siRNA) on cardiac-specific genes. (E-F): Western blotting detection of the effects of TNNI3K knockdown on cardiac-specific proteins. The proteins were measured as previously described. (G): Immunofluorescence detection of cTnT and MHC6 on day 16 in the hTNNI3K, siRNA and normal control groups. (a) Nuclear counterstaining with DAPI. b) MHC6. (c) cTnT. (d) Merged image. hTNNI3K: TNNI3K overexpression, Flag-only: the control of TNNI3K overexpression, siRNA: $T n$ ni3k knockdown, control: non-sense RNA. Scale bars $=25 \mu \mathrm{m}$.

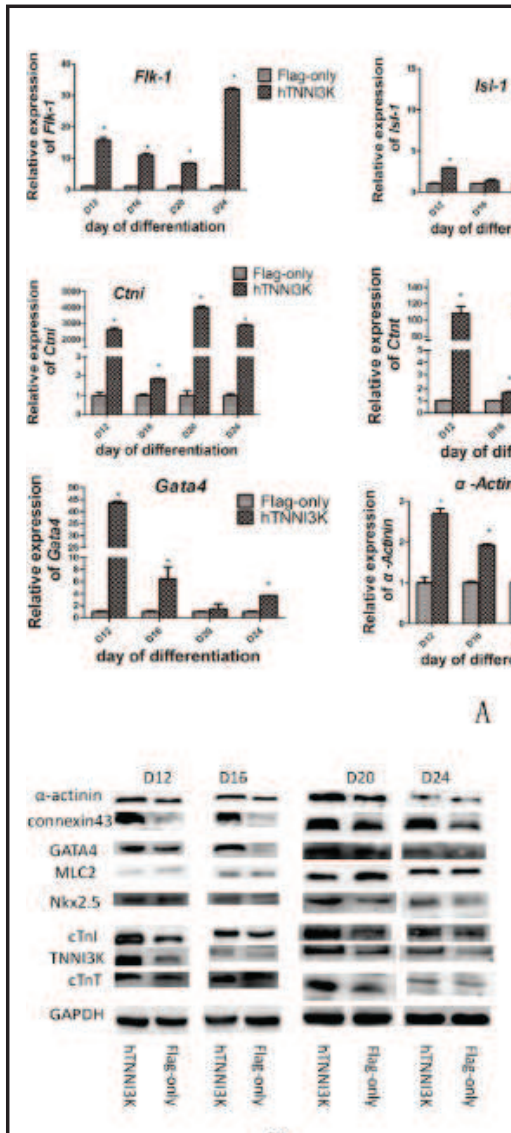

B
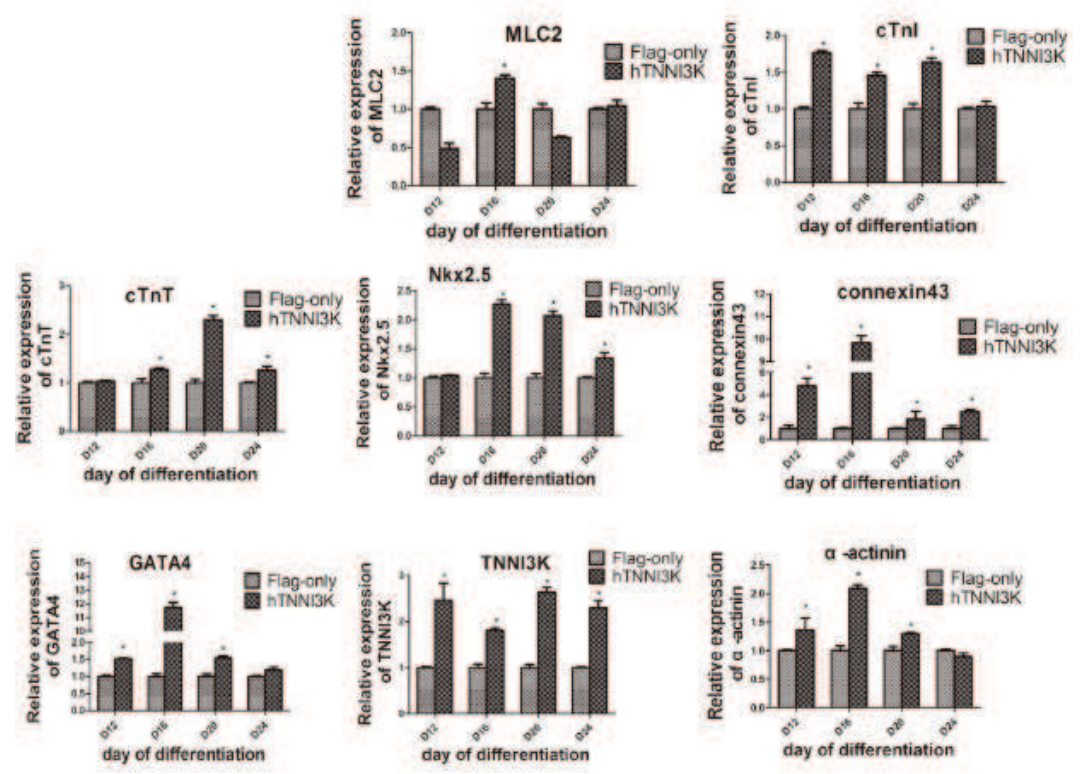

C

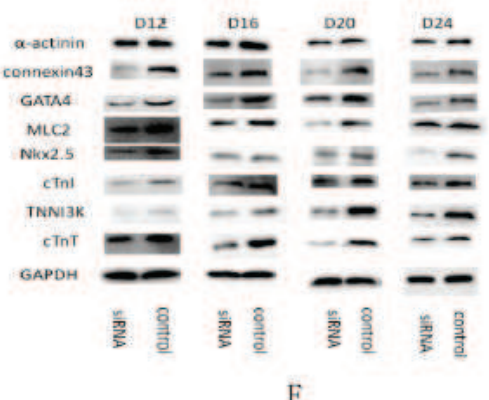

E

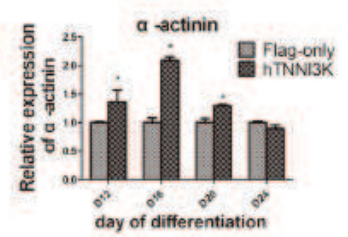

continued

diocytes in dilated or ischemic cardiomyopathy [7]. Interestingly, a series of small-molecule TNNI3K inhibitors were used to reduce mitochondrial-derived superoxide generation, p38 activation, and infarct size when delivered at reperfusion to mimic clinical intervention [15, 34]. Currently, 7-deazapurine, which is potent and selective type I inhibitors of TNNI3K, are 


\section{Cellular Physiology Cell Physiol Biochem 2017;41:381-398 and Biochemistry DOI: 10.1159/000456400 2017 (0) 2017 The Author(s). Published by S. Karger AG, Basel Publisned onine: February 02, 2017 www.karger.com/cpb \\ Wang et al.: TNNI3K and mESCs Differentiation into Cardiomyocytes}

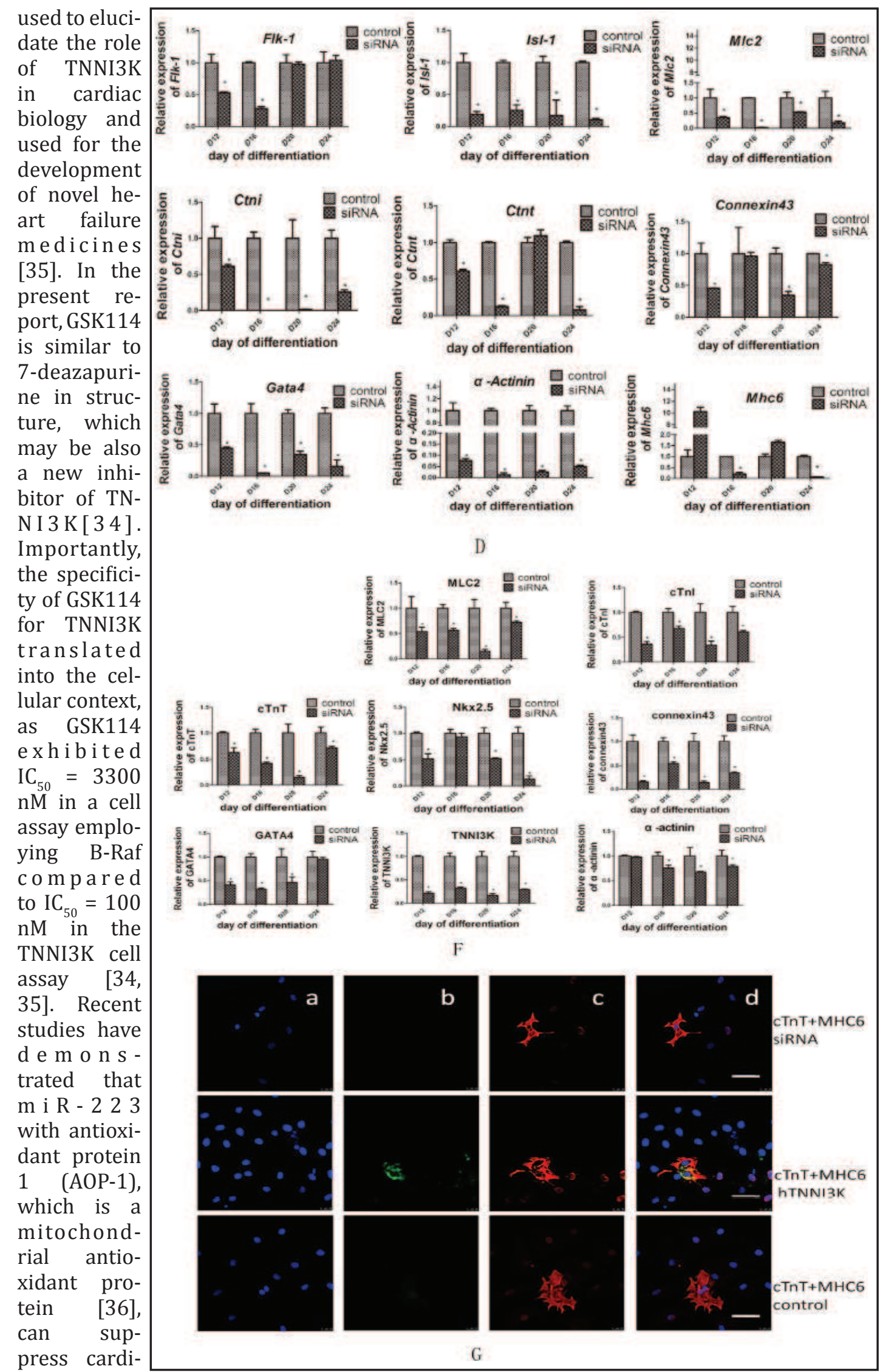




\section{Cellular Physiology \\ Cell Physiol Biochem 2017;41:381-398 and Biochemistry

Fig. 8. TNNI3K overexpression inhibits apoptosis and induces all cardiomyogenesis. A: Real-time PCR detection of the expression levels of Ctnt, connexin 40 and connexin 45 on differentiation $13,16,19$ and 20 days in TNNI3K overexpression group. Positive control: mouse heart tissues. B: western blotting detection of the expression levels of phosphorylated proteins for p38 (P-p38), ERK1/2 (P-ERK), and JNK (P-JNK) in TNNI3K overexpression group, Flag-only group, siRNA group and control group at day12. TNNI3K suppressed the phosphorylations of p38 and JNK. hTNNI3K: TNNI3K overexpression, Flag-only: the control of TNNI3K overexpression, siRNA: Tnni3k knockdown, control: non-sense RNA.

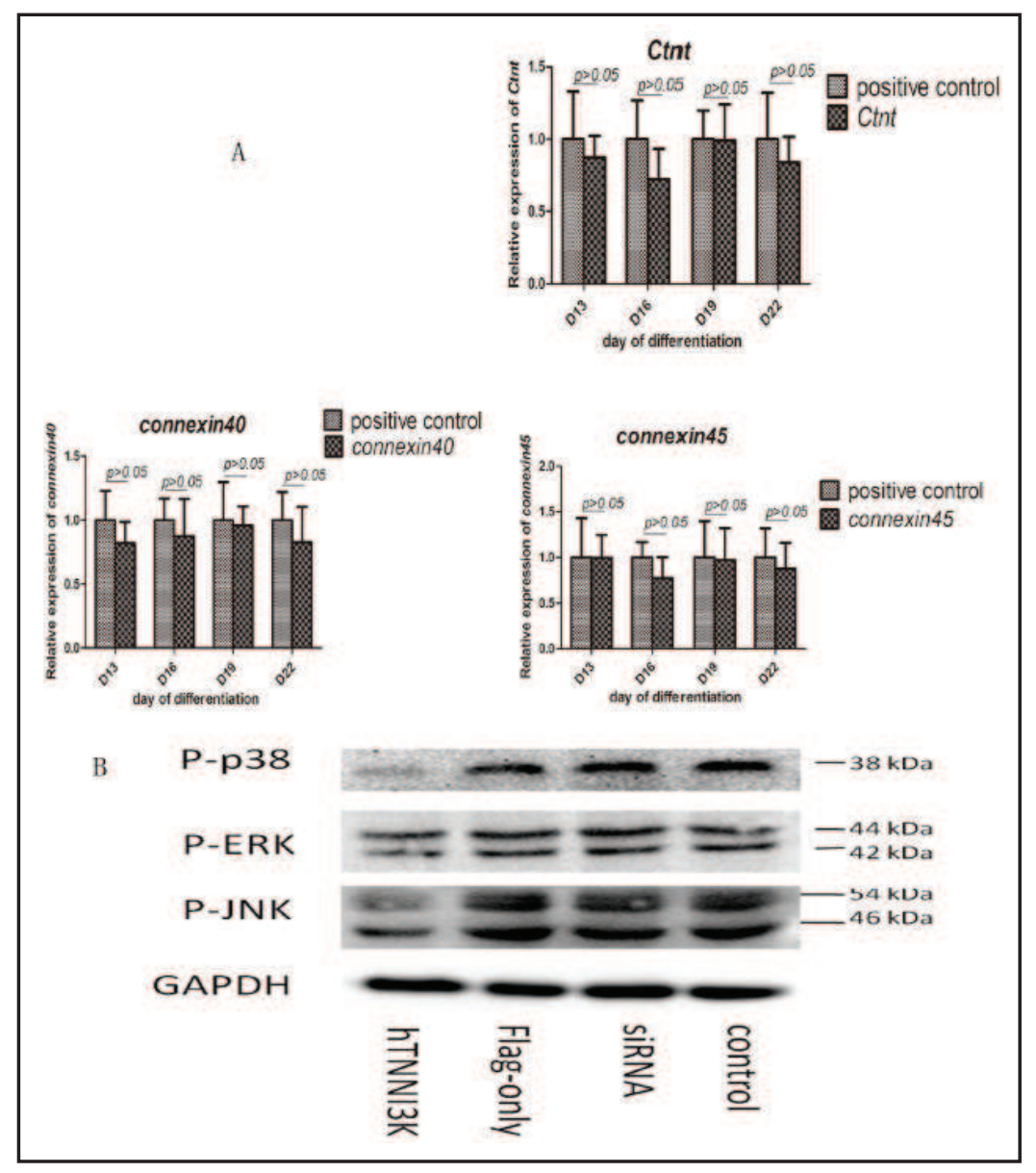

omyocyte hypertrophy via down-regulation of cTnI phosphorylation, which reduces intracellular $\mathrm{Ca}^{2+}$ and the contractility of cardiomyocytes by directly targeting TNNI3K [37]. TNNI3K has been implicated in various cardiac diseases such as, heart failure, cardiomyopathy, ischemia/reperfusion injury and cardiac conduction disorders $[25,38]$.

However, TNNI3K may increase the number of cardiomyogenesis to aid in ventricular remodeling due to myocardial ischemia [16]. TNNI3K over-expression was shown to promote P19Cl6-induced cardiac myogenesis and prevent ischemic myocardial injury by suppressing phosphorylation of cTnI and p38- and JNK-mediated apoptosis [23, 39]. It is noteworthy that P19CL6 strain derives from teratocarcinoma cells, which limits its clinical application. To resolve this limitation, we employed mESCs as the seed cells.

Firstly, we verified that mESCs can spontaneously differentiate into cardiomyocytes with the complete structural and functional capability and that these cells expressed cardiac-specific markers including $\alpha$-actinin, MLC2v, MHC6, connexin43, cTnI and cTnT and the two cardiac transcription factors GATA4 and Nkx2.5. Spontaneous APs were recorded in spontaneously contracting $\mathrm{mESC}$-derived cardiomyocytes. The ventricular-like (V), atrial-like $(\mathrm{A})$, and nodal-like $(\mathrm{N}) \mathrm{mESC}$-derived cardiomyocytes were identified by their characteristic AP properties, i.e., AP amplitude (APA), action potential duration (APD). On assessment of action potential, spontaneously beating ventricular-like cells, atrial-like cells and nodal-like cells were observed; however, due to their relatively lower proportion in mESC-derived cardiomyocytes, single cells were not readily detected. (Fig. 5 A-F). Calcium currents were recorded as described above (Fig.5G-H). During spontaneous mESC differentiation into cardiac myocytes, the proportion of beating EBs were below 30\%, and the proportion of mature cardiomyocytes, as indicated by cTnT positivity, were $<10 \%$ (Fig. 6). These findings indicate low efficiency of spontaneous differentiation. 
Fig. 9. $\mathrm{PKC} \varepsilon$ might be involved to $T N$ $N I 3 K$-overexpression up-regulating expression of cTnT. A-B: Western blot detection of expressions of TNNI3K, PKC $\varepsilon, p-P K C \varepsilon$ and cTnT after administrating $\varepsilon$ V1-2 $(1 \mu \mathrm{M}$, 20 min). “*”: $p<0.05$; "\#": p>0.05.

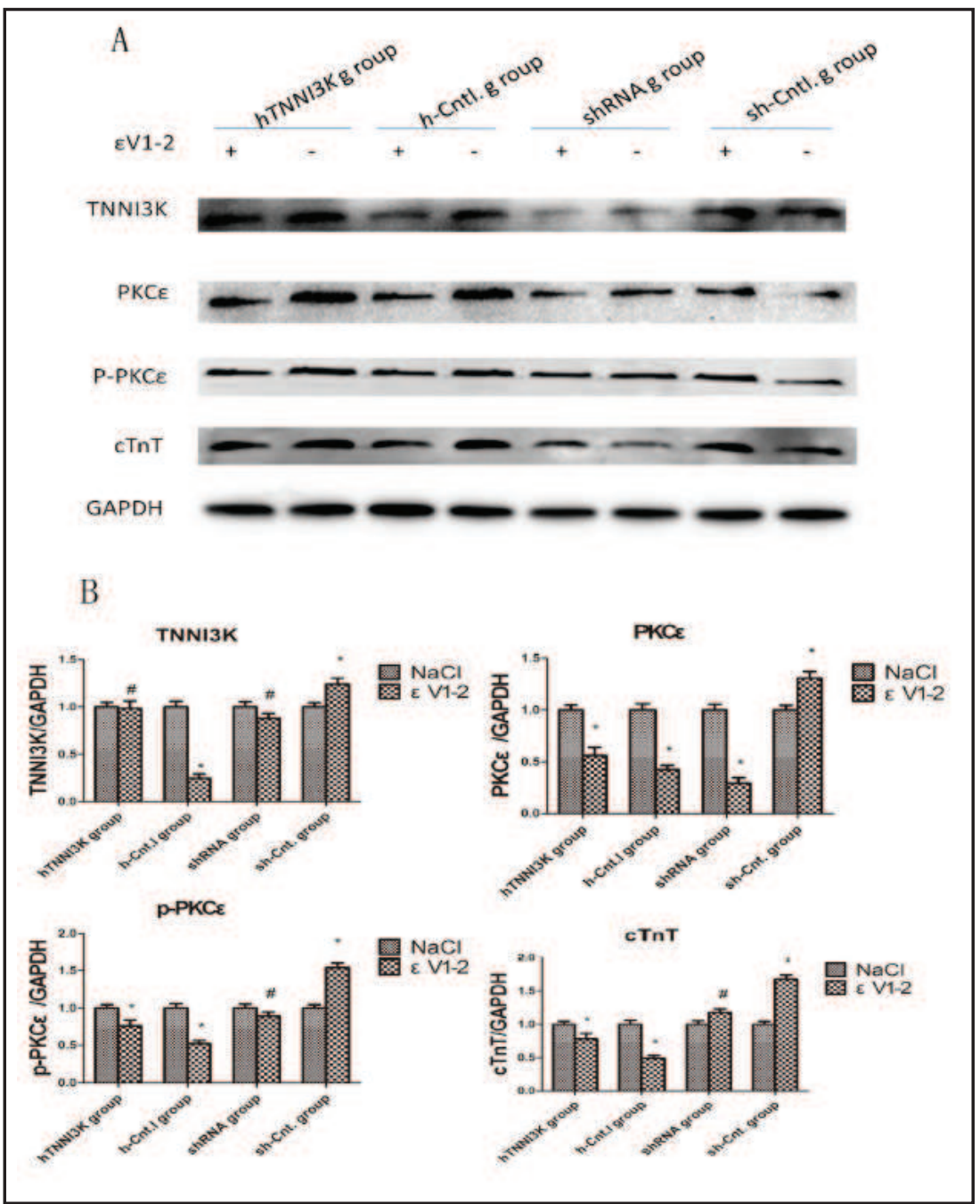

Further investigations for time-course characterization of cardiomyogenesis confirmed the expression of cardiac genes and proteins, including $\alpha$-actinin, MLC2v, MHC6, connexin43, cTnI and cTnT and the two cardiac transcription factors GATA4 and Nkx2.5. Interestingly, four proteins, i.e., connexin 43, MLC2v, cTnT and $\alpha$-actinin, were observed in the undifferentiated mESCs. Connexin43 is known to be present in undifferentiated human ESCs [40] and P19 cells [41]. In this study, connexin43 expression was notably reduced on day-4 during the early phase of differentiation of ESCs; however, with continued differentiation, connexin43 expression was detected again on day-12 at a level that was similar to that in the early differentiation phase [42]. This time-course expression of connexin43 was likely due to cTnT and MLC2v and was similar to that of $\alpha$-actinin with only slight differences with respect to the differentiation time. The cardiac transcription factor GATA4 remained expressed at low levels during the early cardiac differentiation stage. However, the other cardiac transcription factor Nkx2.5 was not detected until the $14^{\text {th }}$ day of differentiation. Notably, MHC6 expression also remained absent in the early differentiation stage but appeared rapidly between day-12 and day- 14 .

In the present study, we observed that overexpressed TNNI3K increased the numbers of cardiomyocytes, beating EB masses and CTnT positive cells, and enhanced the frequency of beating cardiomyocytes by inducing suppression of the signal pathway for p38- and JNKmediated apoptosis (Fig. 8). We observed an increase of cTnT+ positive cells from $2-4 \%$ in differentiated Flag-only cells to $5-25 \%$ in TNNI3K-overexpressing embryoid bodies, which exceeded that of Tbx5-overexpressing embryoid bodies [43]. 


\section{Cellular Physiology Cell Physiol Biochem 2017;41:381-398 \begin{tabular}{ll|l} 
DOI: 10.1159/000456400 & (O) 2017 The Author(s). Published by S. Karger AG, Basel
\end{tabular} Publisned online: February 02, 2017 www.karger.com/cpb \\ Wang et al.: TNNI3K and mESCs Differentiation into Cardiomyocytes}

To date, TNNI3K can directly interact with cTnI through phosphorylating $[9,12]$. It should be noted the implicated cTnI phosphorylation sites involve residues that have been established as protein kinase C (PKC) or protein kinase A (PKA) phosphorlation sites [24, 25]. Dubois-Deruy et al. [26] found that decreased TnTpSer208 levels in the left ventricles of $\mathrm{HF}$ male Wistar rats were associated with reduced expression of $\mathrm{PKC} \varepsilon$, but not of other cardiac PKC isoforms. Multiple Ser and Thr residues in the middle and C-terminal regions of cTnT have been reported to be phosphorylated by PKC, especially PKCe in vivo and in vitro $[27,28]$. Above all, phosphorylation of cTnT by PKC $\varepsilon$ enhanced cardiac contractility, which was reduced in heart failure due to decreased level of PKCE [26]. To understand the relationship of TNNI3K, PKC $\varepsilon$ with cTnT, we detected that in hTNNI3K group, the expression of $c \mathrm{TnT}$ was downregulated by $\varepsilon \mathrm{V} 1-2$, as well as the expressions of $\mathrm{PKC} \varepsilon / \mathrm{p}-\mathrm{PKC} \varepsilon$, but the expression of TNNI3K was not changed by $\varepsilon$ V1-2. In siRNA group, the expression of PKC $\varepsilon$ was downregulated by siRNA of TNNI3K. Therefore, the result indicated that PKC $\varepsilon$ was involved to TNNI3K-overexpression induced up-regulating expression of cTnT.

In conclusion, the present study demonstrated that TNNI3K, can promote the cardiomyogenesis with increasing beating masses and cTnT-positive cells, facilitating differentiation through suppression of the ERK and the p38- and JNK-modulated apoptosis, and up-regulating expression of cTnT though PKC $/ \mathrm{p}-\mathrm{PKC} \varepsilon$. TNNI3K activity depending on genomic techniques or artificially synthesized molecules may be a novel therapeutic strategy for the treatment of ischemic heart disease or myocardial infarction.

\section{Acknowledgments}

This article is partly supported by National Natural Scientific Foundation (81100118, 81370203 and 81461148026), Specialized Research Fund for the Doctoral Program of Higher Education of China (20111106110013), Specialized Research Personnel Fund of Fu Wai Hospital (2012-FWXX02 and 2008-F017), PUMC Youth Fund (2016-XHQN06) and the Beijing Municipal Science and Technology Commission (Z141100000214006).

\section{Disclosure Statement}

The authors have no potential conflicts of interest to declare.

\section{References}

1 Zhao Y, Meng XM, Wei YJ, Zhao XW, Liu DQ Cao HQ, Liew CC, Ding JF: Cloning and characterization of a novel cardiac-specific kinase that interacts specifically with cardiac troponin i. J Mol Med (Berl) 2003;81:297-304.

-2 Val C. Sheffield MEP, Darryl Nishimura, John S. Beck, Trudy L. Burns MAB, Edwin M. Stone, Shivanand R. Patil, Lauer RM: Identification of a complex congenital heart defect susceptibility locus by using DNA pooling and shared segment analysis. Hum Mol Genet 1997;6:117-121.

-3 Tang H, Xiao K, Mao L, Rockman HA, Marchuk DA: Overexpression of tnni3k, a cardiac-specific mapkkk, promotes cardiac dysfunction. J Mol Cell Cardiol 2013;54:101-111.

4 Wang H, Chen C, Song X, Chen J, Zhen Y, Sun K, Hui R: Mef2c is an essential regulatory element required for unique expression of the cardiac-specific cark gene. J Cell Mol Med 2008;12:304-315.

-5 Trifonov VA, Dementyeva PV, Larkin DM, O'Brien PC, Perelman PL, Yang F, Ferguson-Smith MA, Graphodatsky AS: Transcription of a protein-coding gene on b chromosomes of the siberian roe deer (capreolus pygargus). BMC Biol 2013;11:90.

-6 Zhu Y, Lu L, Xu L, Yang H, Jiang S, Chen YH: Identification of a gp41 core-binding molecule with homologous sequence of human tnni3k-like protein as a novel human immunodeficiency virus type 1 entry inhibitor. J Virol 2010;84:9359-9368. 


\section{Cellular Physiology Cell Physiol Biochem 2017;41:381-398 and Biochemistry DOI: 10.1159/000456400 102017 The Author(s). Published by S. Karger AG, Basel

-7 Wei YJ, Cui CJ, Huang YX, Zhang XL, Zhang H, Hu SS: Upregulated expression of cardiac ankyrin repeat protein in human failing hearts due to arrhythmogenic right ventricular cardiomyopathy. Eur J Heart Fail 2009;11:559-566.

8 Feng Y, Cao HQ, Liu Z, Ding JF, Meng XM: Identification of the dual specificity and the functional domains of the cardiac-specific protein kinase tnni3k. Gen Physiol Biophys 2007;26:104-109.

-9 Wang H, Wang L, Song L, Zhang YW, Ye J, Xu RX, Shi N, Meng XM: Tnni3k is a novel mediator of myofilament function and phosphorylates cardiac troponin i. Braz J Med Biol Res 2013;46:128-137.

10 Luft FC: Hearts of this ilk rely on tnni3k, a mapkkk that regulated tnni3. J Mol Med (Berl) 2003;81:279-280.

11 Wheeler FC, Tang H, Marks OA, Hadnott TN, Chu PL, Mao L, Rockman HA, Marchuk DA: Tnni3k modifies disease progression in murine models of cardiomyopathy. PLoS Genet 2009;5:e1000647.

12 Wang X, Wang J, Su M, Wang C, Chen J, Wang H, Song L, Zou Y, Zhang L, Zhang Y, Hui R: Tnni3k, a cardiacspecific kinase, promotes physiological cardiac hypertrophy in transgenic mice. PLoS One 2013;8:e58570.

13 Wang L, Wang H, Ye J, Xu RX, Song L, Shi N, Zhang YW, Chen X, Meng XM: Adenovirus-mediated overexpression of cardiac troponin i-interacting kinase promotes cardiomyocyte hypertrophy. Clin Exp Pharmacol Physiol 2011;38:278-284.

14 Wiltshire SA, Leiva-Torres GA, Vidal SM: Quantitative trait locus analysis, pathway analysis, and consomic mapping show genetic variants of tnni3k, fpgt, or h28 control susceptibility to viral myocarditis. J Immunol 2011;186:6398-6405.

-15 Vagnozzi RJ, Gatto GJ, Jr., Kallander LS, Hoffman NE, Mallilankaraman K, Ballard VL, Lawhorn BG, Stoy P, Philp J, Graves AP, Naito Y, Lepore JJ, Gao E, Madesh M, Force T: Inhibition of the cardiomyocyte-specific kinase tnni3k limits oxidative stress, injury, and adverse remodeling in the ischemic heart. Sci Transl Med 2013;5:207ra141.

16 Lodder EM, Scicluna BP, Milano A, Sun AY, Tang H, Remme CA, Moerland PD, Tanck MW, Pitt GS, Marchuk DA, Bezzina CR: Dissection of a quantitative trait locus for pr interval duration identifies tnni3k as a novel modulator of cardiac conduction. PLoS Genet 2012;8:e1003113.

17 Cornelis MC, Rimm EB, Curhan GC, Kraft P, Hunter DJ, Hu FB, van Dam RM: Obesity susceptibility loci and uncontrolled eating, emotional eating and cognitive restraint behaviors in men and women. Obesity (Silver Spring) 2014;22:E135-141.

18 Mitchell JA, Hakonarson H, Rebbeck TR, Grant SF: Obesity-susceptibility loci and the tails of the pediatric bmi distribution. Obesity (Silver Spring) 2013;21:1256-1260.

-19 Kitamoto A, Kitamoto T, Mizusawa S, Teranishi H, So R, Matsuo T, Nakata Y, Hyogo H, Ochi H, Nakamura T, Kamohara S, Miyatake N, Kotani K, Komatsu R, Itoh N, Mineo I, Wada J, Yoneda M, Nakajima A, Funahashi T, Miyazaki S, Tokunaga K, Masuzaki H, Ueno T, Chayama K, Hamaguchi K, Yamada K, Hanafusa T, Oikawa S, Sakata T, Tanaka K, Matsuzawa Y, Nakao K, Sekine A, Hotta K: Nudt3 rs206936 is associated with body mass index in obese japanese women. Endocr J 2013;60:991-1000.

-20 Williams MJ, Almen MS, Fredriksson R, Schioth HB: What model organisms and interactomics can reveal about the genetics of human obesity. Cell Mol Life Sci 2012;69:3819-3834.

-21 McCaffery JM, Papandonatos GD, Peter I, Huggins GS, Raynor HA, Delahanty LM, Cheskin LJ, Balasubramanyam A, Wagenknecht LE, Wing RR, Genetic Subgroup of Look A, Look ARG: Obesity susceptibility loci and dietary intake in the look ahead trial. Am J Clin Nutr 2012;95:1477-1486.

-22 Hong KW, Oh B: Recapitulation of genome-wide association studies on body mass index in the korean population. Int J Obes (Lond) 2012;36:1127-1130.

-23 Lai ZF, Chen YZ, Feng LP, Meng XM, Ding JF, Wang LY, Ye J, Li P, Cheng XS, Kitamoto Y, Monzen K, Komuro I, Sakaguchi N, Kim-Mitsuyama S: Overexpression of tnni3k, a cardiac-specific map kinase, promotes p19cl6derived cardiac myogenesis and prevents myocardial infarction-induced injury. Am J Physiol Heart Circ Physiol 2008;295:H708-716.

24 Layland J, Solaro RJ, Shah AM: Regulation of cardiac contractile function by troponin i phosphorylation. Cardiovasc Res 2005;66:12-21.

25 Milano A, Lodder EM, Bezzina CR: Tnni3k in cardiovascular disease and prospects for therapy. J Mol Cell Cardiol 2015;82:167-173.

-26 Dubois-Deruy E, Belliard A, Mulder P, Bouvet M, Smet-Nocca C, Janel S, Lafont F, Beseme O, Amouyel P, Richard V, Pinet F: Interplay between troponin t phosphorylation and o-n-acetylglucosaminylation in ischaemic heart failure. Cardiovasc Res 2015;107:56-65. 


\section{Cellular Physiology \\ Cell Physiol Biochem 2017;41:381-398 and Biochemistry \begin{tabular}{l|l}
\hline DOI: $10.1159 / 000456400$ & (c) 2017 The Author(s). Published by S. Karger AG, Basel
\end{tabular} \\ Publisned online: February 02, 2017 www.karger.com/cpb}

Wang et al.: TNNI3K and mESCs Differentiation into Cardiomyocytes

27 Wei B, Jin JP: Tnnt1, tnnt2, and tnnt3: Isoform genes, regulation, and structure-function relationships. Gene 2016;582:1-13.

28 SV P: Troponin t: Genetics, properties and function. J Muscle Res Cell Motil 1998;19:575-602.

29 Shinde V, Brungs S, Henry M, Wegener L, Nemade H, Rotshteyn T, Acharya A, Baumstark-Khan C, Hellweg CE, Hescheler J, Hemmersbach R, Sachinidis A: Simulated microgravity modulates differentiation processes of embryonic stem cells. Cell Physiol Biochem 2016;38:1483-1499.

-30 Yin M, Yuan Y, Cui Y, Hong X, Luo H, Hu X, Tang M, Hescheler J, Xi J: Puerarin suppresses the self-renewal of murine embryonic stem cells by inhibition of rest-mir-21 regulatory pathway. Cell Physiol Biochem 2015;37:527-536.

-31 Niehoff J, Matzkies M, Nguemo F, Hescheler J, Reppel M: Beat rate variability in murine embryonic stem cell-derived cardiomyocytes: Effect of antiarrhythmic drugs. Cell Physiol Biochem 2016;38:646-658.

-32 Hannes T, Wolff M, Doss MX, Pfannkuche K, Haustein M, Muller-Ehmsen J, Sachinidis A, Hescheler J, Khalil M, Halbach M: Electrophysiological characteristics of embryonic stem cell-derived cardiomyocytes are cell line-dependent. Cell Physiol Biochem 2015;35:305-314.

33 Xu R, Srinivasan SP, Sureshkumar P, Nembo EN, Schafer C, Semmler J, Matzkies M, Albrechtsen M, Hescheler J, Nguemo F: Effects of synthetic neural adhesion molecule mimetic peptides and related proteins on the cardiomyogenic differentiation of mouse embryonic stem cells. Cell Physiol Biochem 2015;35:2437-2450.

-34 Lawhorn BG, Philp J, Graves AP, Shewchuk L, Holt DA, Gatto GJ, Jr., Kallander LS: Gsk114: A selective inhibitor for elucidating the biological role of tnni3k. Bioorg Med Chem Lett 2016;26:3355-3358.

-35 Lawhorn BG, Philp J, Zhao Y, Louer C, Hammond M, Cheung M, Fries H, Graves AP, Shewchuk L, Wang L, Cottom JE, Qi H, Zhao H, Totoritis R, Zhang G, Schwartz B, Li H, Sweitzer S, Holt DA, Gatto GJ, Jr., Kallander LS: Identification of purines and 7-deazapurines as potent and selective type i inhibitors of troponin i-interacting kinase (tnni3k). J Med Chem 2015;58:7431-7448.

-36 Feng Y, Liu DQ, Wang Z, Liu Z, Cao HQ, Wang LY, Shi N, Meng XM: Aop-1 interacts with cardiac-specific protein kinase tnni3k and down-regulates its kinase activity. Biochemistry (Mosc) 2007;72:1199-1204.

37 Wang YS, Zhou J, Hong K, Cheng XS, Li YG: Microrna-223 displays a protective role against cardiomyocyte hypertrophy by targeting cardiac troponin i-interacting kinase. Cell Physiol Biochem 2015;35:1546-1556.

-38 Theis JL, Zimmermann MT, Larsen BT, Rybakova IN, Long PA, Evans JM, Middha S, de Andrade M, Moss RL, Wieben ED, Michels VV, Olson TM: Tnni3k mutation in familial syndrome of conduction system disease, atrial tachyarrhythmia and dilated cardiomyopathy. Hum Mol Genet 2014;23:5793-5804.

-39 Lai ZF: Tnni3k could be a novel molecular target for the treatment of cardiac diseases. Recent Pat Cardiovasc Drug Discov 2009;4:203-210.

40 Wong RC, Pebay A, Nguyen LT, Koh KL, Pera MF: Presence of functional gap junctions in human embryonic stem cells. Stem Cells 2004;22:883-889.

-41 van der Heyden MA, Rook MB, Hermans MM, Rijksen G, Boonstra J, Defize LH, Destree OH: Identification of connexin43 as a functional target for wnt signalling. J Cell Sci 1998;111:1741-1749.

-42 van Kempen M, van Ginneken A, de Grijs I, Mutsaers N, Opthof T, Jongsma H, van der Heyden M: Expression of the electrophysiological system during murine embryonic stem cell cardiac differentiation. Cell Physiol Biochem 2003;13:263-270.

43 Herrmann F, Bundschu K, Kuhl SJ, Kuhl M: Tbx5 overexpression favors a first heart field lineage in murine embryonic stem cells and in xenopus laevis embryos. Dev Dyn 2011;240:2634-2645. 